\title{
Diagnóstico y tratamiento de las periimplantitis. Actualización en el diagnóstico clínico y en el tratamiento de las periimplantitis
}

\author{
GARCÍA-CALDERÓN M* \\ CABEZAS TALAVERO J** \\ GALLEGO ROMERO D** \\ TORRES LAGARES $\mathbf{D} * *$
}

García-Calderón M, Cabezas Talavero J, Gallego Romero D, Torres Lagares D. Av Periodon Implantol. 2004; 16, 1: 9-18.

\begin{abstract}
RESUMEN
En el presente capítulo realizamos una descripción de las investigaciones y hallazgos más importantes aparecidos recientemente en la literatura implantológica, los cuales inciden de una forma más significativa en el diagnóstico clínico y su aplicación en el tratamiento de las periimplantitis por parte del dentista. Aunque todavía no existe claridad ni consenso en los protocolos de actuación terapéutica, hemos realizado un meticuloso análisis de los conocimientos aportados por los diferentes investigadores, y describimos su aplicación más racional al hilo de las últimas investigaciones.
\end{abstract}

\section{PALABRAS CLAVE}

Periimplantitis. Diagnóstico. Tratamiento

Aceptado para publicación: Julio 2003

\section{INTRODUCCIÓN}

La pérdida de hueso periimplantario ha sido atribuida generalmente a diferentes procesos que incluyen desde una técnica quirúrgica inadecuada, fracaso en conseguir la osteointegración, carga prematura, sobrecarga biomecánica, infección periimplantaria y a una respuesta alterada del huésped. Sin embargo, de todos ellos son la infección periimplantaria y la sobrecarga biomecánica los factores etiológicos que se involucran en la pérdida progresiva de hueso en implantes que ya están en función. Su aparición requiere un diagnóstico y tratamiento precoz para evitar el fracaso del implante (1).

Clásicamente se ha aceptado esta dualidad etiológica aunque la evidencia científica de una y otra en la génesis de la periimplantitis es bastante diferente. En la actualidad como veremos a lo largo de esta revisión existe abundante bibliografía que sustenta el papel de las bacterias en la etiología de la periimplantitis. Sin embargo, en humanos, no existe evidencia suficiente que sustente que la sobrecarga oclusal se manifieste por pérdida progresiva de hueso marginal que lleve a la pérdida de osteointegración $(2,3)$.

Periimplantitis se define como un proceso inflamatorio que afecta a los tejidos que rodean a un implante osteointegrado en función, provocando la pérdida de soporte óseo, mientras que se define mucositis periimplantaria como un proceso inflamatorio en ausencia de la pérdida de hueso. La mucositis periimplantaria sería un proceso reversible similar a la gingivitis (4). Sabemos que la pérdida de hueso asociada a la Periimplantitis suele ser circunferencial o en forma de embudo, a diferencia de la pérdida ósea de causa periodontal que se localiza en un lado (defectos angulares) (5). Además, la morfología de los

* Médico Estomatólogo. Doctor en Odontología. Profesor Master de Cirugía Bucal de la Universidad de Sevilla.

** Odontólogo. Master en Cirugía Bucal de la Universidad de Sevilla. 
defectos óseos parece estar influenciada por la forma macroscópica de los implantes y tener características diferentes en función del diseño del implante, así como de la estructura de superficie de los mismos. De esta forma, alrededor de los implantes roscados aparecen defectos más aplanados, son defectos horizontales (Fig. 1), y alrededor de los implantes cilíndricos los defectos óseos tiene forma más angulares, es decir son más verticales (Fig. 2).

Las características de superficie pueden influir en la morfología del defecto. Está demostrado que los implantes con superficies recubiertas pueden hospedar y perpetuar infecciones causando pérdida de hueso de forma vertical (6). De este modo estas características de los implantes influirán de forma notable tanto en el diagnóstico como en el enfoque terapéutico ante una periimplantitis.

Durante los primeros años del uso de los implantes osteointegrados para la rehabilitación protésica de la desdentación, la frecuencia de aparición de periimplantitis fue muy escasa, posiblemente porque la indicación más frecuente era en el paciente totalmente desdentado, el cual tenía ausencia de la flora bacteriana periodontal habitual y periodontopatógena. Sin embargo, es a raíz de la generalización de su uso y del aumento de indicaciones clínicas ocurrido en la última década del siglo pasado (7), sobre todo en pacientes parcialmente desdentados que eran portadores de enfermedad periodontal, cuando la irrupción de esta patología se hace mucho más prevalente.

\section{RESPUESTA INFLAMATORIA}

La mucosa masticatoria alrededor de los implantes y la encía alrededor de los dientes responden de forma similar a la formación de nueva placa con el desarro-

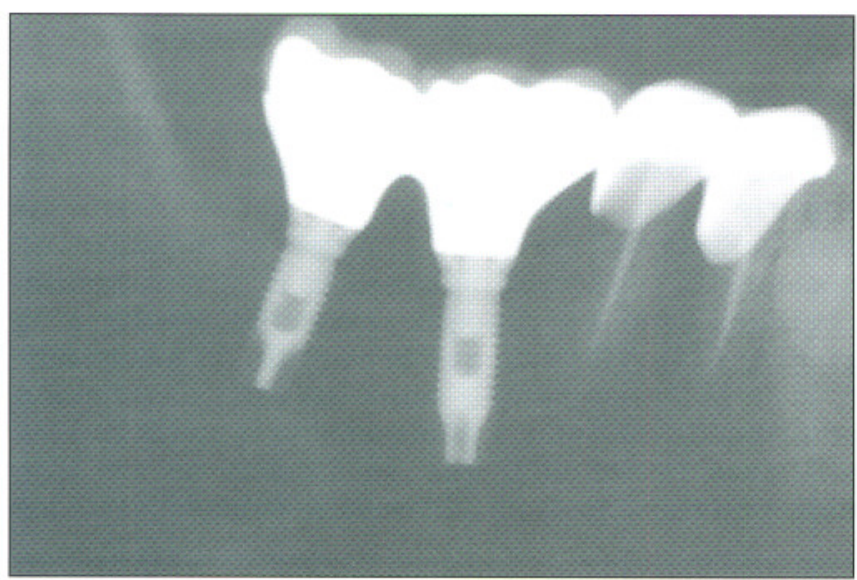

Fig. 1. Defectos óseos provocados por la periimplantitis en implantes roscados. llo de una lesión inflamatoria. Podemos encontrar un infiltrado de células inflamatorias en el tejido conectivo adyacente al epitelio de unión largo similar en los dientes y en la mucosa periimplantaria. Es más, la magnitud y composición de las lesiones en ambos tejidos tienen características comunes, ya que la mucosa periimplantaria y la encía alrededor de los dientes tienen parecido potencial, para responder a la formación de placa temprana (8). Sin embargo a partir de las 3 semanas, los dos infiltrados en el tejido conectivo que tenían las mismas características, se diferencian en que la extensión apical es más pronunciada en la mucosa periimplantaria que en la encía. Por esta vía los resultados de la destrucción ósea son más pronunciados en los implantes que en los dientes, el tamaño de la lesión de los tejidos blandos es más grande en los implantes que en los dientes y la lesión en los implantes se extiende más frecuentemente al hueso medular (9).

En conclusión, para los dientes la acumulación de placa de larga evolución no conlleva la extensión de la lesión inflamatoria. Sin embargo para los implantes, bajo idénticas condiciones experimentales, se observó una diseminación más importante en dirección apical del infiltrado de células inflamatorias. Esto implica que los mecanismos de defensa de la encía son más efectivos en prevenir la propagación apical de la microflora de la bolsa, que los de la mucosa periimplantaria.

Existe otro factor en relación con la salud de los tejidos blandos periimplantarios que puede incidir de forma notoria a la hora de la respuesta de los tejidos ante la agresión ya sea traumática o infecciosa. Mucho se ha enfatizado en Periodoncia sobre la necesidad o no de la presencia de una banda de tejido insertado, queratinizado, que rodee a los dientes. Sabemos que dicha presencia no es imprescindible para la obtención de salud periodontal, pero ¿es importante la presencia de

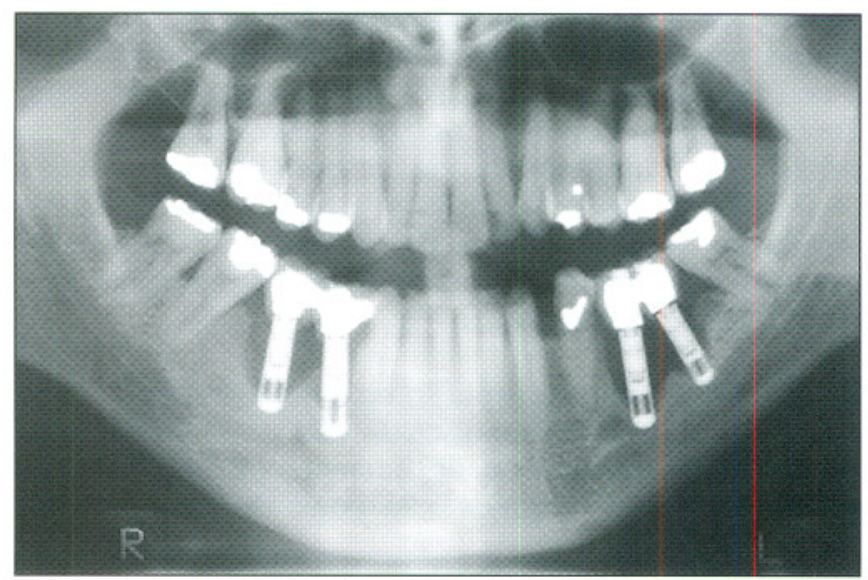

Fig. 2. Defectos óseos angulares típicos alrededor de implantes cilindricos impactado. 
encía queratinizada alrededor de los implantes para conservar o mantener la salud de los tejidos periimplantarios? En la literatura implantológica está recogido que los implantes rodeados de mucosa alveolar, móvil, no queratinizada, parecen ser más susceptibles a la progresión de la periimplantitis (10) (Fig. 3). Sin embargo no hay estudios clínicos que soporten la idea de que la ausencia de encía queratinizada conlleva a una mayor frecuencia y progresión más rápida de periimplantitis (11).

No obstante la lógica, y la experiencia y observación clínica nos demuestran que la presencia de una zona de encía queratinizada, insertada, puede ofrecer una mayor resistencia a las injurias y traumatismos que pueden llevar a la pérdida del sellado alrededor de los implantes provocando una facilitación a la invasión y colonización por bacterias periimplantopatógenas del surco periimplantario (Fig. 4).

\section{MICROBIOLOGÍA}

Existe amplia evidencia que soporta la similitud entre placa bacteriana y la enfermedad Periimplantaria, muy parecida a la relación causa-efecto entre placa bacteriana y enfermedad periodontal. Esta causalidad se ha podido corroborar en estudios de mucositis inducida experimentalmente $(12,13)$, comparando los diferentes microorganismos de sitios enfermos y sitios en salud $(14,15)$, o por la comprobación de la mejoría clínica de la periimplantitis con terapia antimicrobiana $(16,17)$. Assí, los patógenos periimplantarios identificados habitualmente en los citados estudios eran similares a los encontrados en sitios con enfermedad periodontal. De esta forma Becker y Becker concluían que en los implantes dentales con profundidades de sondaje superiores a $6 \mathrm{~mm}$ la flora bacteriana que los colonizaba se asociaba con una mayor presencia porcentual de bacterias anaerobias

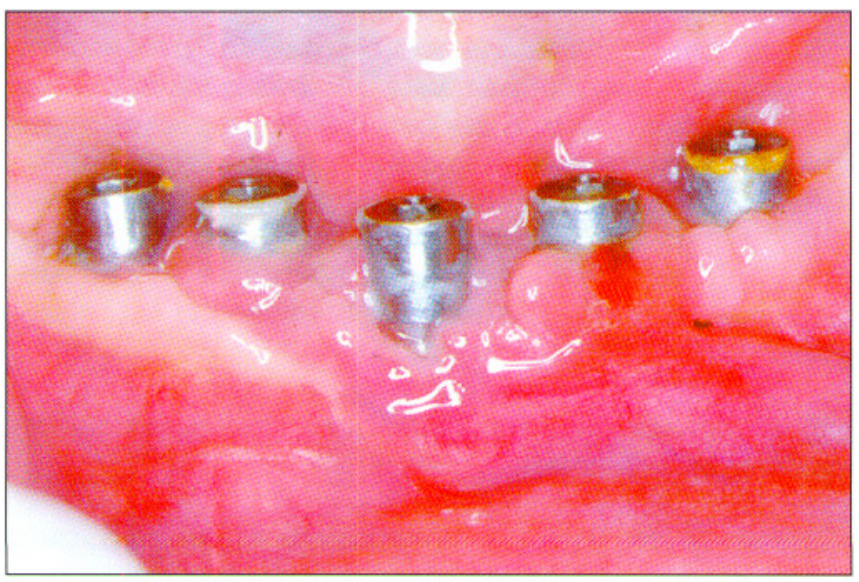

Fig. 3. Implantes rodeados de mucosa alveolar, no queratinizada.
Gram negativas. Identificaban por medio de pruebas de $\mathrm{ADN}$ en los implantes que estaban fracasando niveles moderados de Actinobacillus actinemycetemcomitans, Porphyromona gingivalis y Prevotella intermedius (18). En otro estudio se pudo comprobar que en sitios en salud de pacientes con implantes con y sin enfermedad inflamatoria se encontraron menores cantidades de bacterias, siendo más frecuentes los cocos y bacilos Gram positivos facultativos, comportándose los tejidos periimplantarios de forma muy similar a los tejidos periodontales, y por ello concluían que las lesiones periimplantarias deben ser consideradas como infecciones sitio-específicas, las cuales hospedan un alto número de patógenos periodontales, principalmente Bacilos anaerobios Gram negati$\operatorname{vos}(6)$. Otros autores pudieron establecer como con la eliminación de la flora periodontopatógena que provoca la periodontitis desparecía la posibilidad de colonización del surco o bolsa periimplantaria. Evaluaron a pacientes desdentados que habían sido tratados con implantes y con historia anterior de enfermedad periodontal, razón por la que se extrajeron los dientes con gran movilidad. Los resultados indicaron que cuando los dientes afectados periodontalmente eran extraídos antes de la inserción de implantes, las microbiota periimplantaria subsiguiente estaba compuesta por bacterias que se asocian con salud periodontal. Estos resultados sugieren que la eliminación de patógenos en el entorno subgingival por medio de la terapia periodontal o por extracciones de los dientes muy afectados, tiene un efecto beneficioso en la microflora alrededor de los implantes (19).

Toda esta información sugiere consideraciones a tener muy en cuenta a la hora de analizar el enfoque preventivo y terapéutico de la periimplantitis, realizándolo de una forma similar a la de la enfermedad periodontal habida cuenta que estamos tratando de una flora bacteriana muy similar, siendo su procedencia la bolsa periodontal enferma o contaminada.

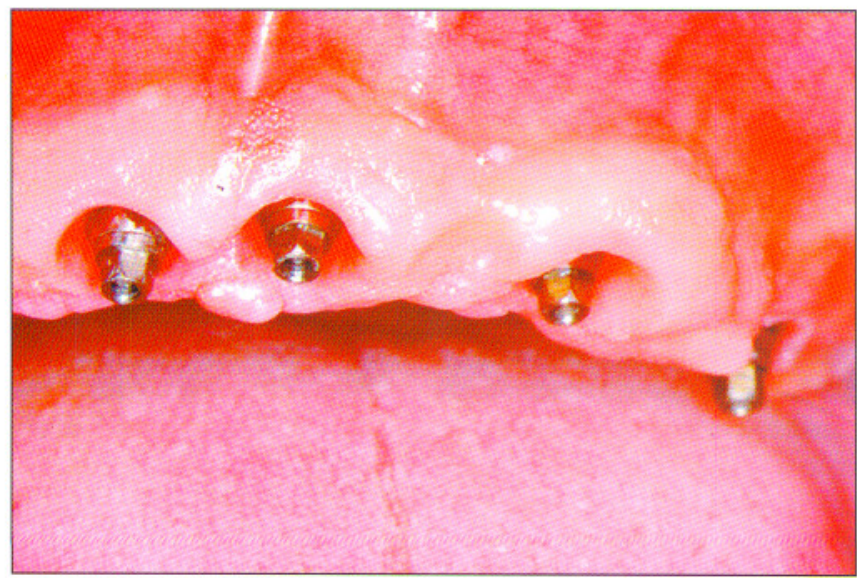

Fig. 4. Implantes rodeados de encía queratinizada. 


\section{DIAGNÓSTICO DE PERIIMPLANTITIS}

La preservación de la altura del hueso marginal se considera crucial para el mantenimiento de los implantes y es a menudo usado como un criterio de éxito de los diferentes sistemas de implantes (20). Clásicamente se ha considerado una pérdida vertical ósea menor de 0,2 mm durante el primer año y de 0,1 en los años posteriores como uno de los criterios de éxito más importantes. La detección de pequeños cambios o de alteraciones en la densidad ósea requieren la realización de radiografías estandarizadas y muy periódicas, siempre con la misma angulación e idénticas características de realización, adecuadas para la ejecución de trabajos de investigación clínica, muy lejos de las posibilidades habituales que se pueden hacer en la clínica diaria. Los procedimientos diagnósticos deberán incluir la medición de parámetros sensibles para detectar precozmente signos y síntomas de infección. Se recomienda iniciar el proceso diagnóstico con el chequeo de la movilidad, profundidad de sondaje y presencia de sangrado al sondaje y supuración. Estos procedimientos clínicos tienen una muy buena relación costo-efectividad con resultados instantáneos. Las radiografías y los análisis microbiológicos se realizarán secuencialmente, dependiendo de los datos que encontremos en la exploración clínica. Por ello, siguiendo a Mombelli A y cols. (20-22), todo clínico en la visitas de revisión y mantenimiento de los pacientes portadores de tratamientos con implantes osteointegrados debe plantearse las siguientes cuestiones:

¿Es la profundidad de sondaje periimplantario $>3 \mathrm{~mm}$ ?

Los implantes en salud por lo general presentan profundidades de sondaje de aproximadamente $3 \mathrm{~mm}$, y la localización del nivel de hueso periimplantario cabe esperar que se encuentre a 1-1,5 mm por debajo del nivel de sondaje, dependiendo del tipo de implante y características de superficie del mismo. Una excepción pueden ser profundidades de sondaje mayores de $3 \mathrm{~mm}$ que están causadas por una localización submucosa de la conexión entre el implante y la supraestructura protésica. Otras veces los tejidos pueden estar posicionados por encima del hombro del implante por razones estéticas (pseudobolsas periimplantarias).

En determinadas ocasiones profundidades de sondaje aumentadas, por encima de los 3-4 mm, pueden estar ocasionadas por la presencia de inflamación y tumefacción de los tejidos blandos periimplantarios, pudiendo ser corregida dicha situación con procedimientos de control de placa, mejora de la higiene oral, retirada temporal de la restauración protésica y aplicación de antisépticos locales (enjuagues), aunque sabemos que la utilidad de los enjuagues en bolsas más profundas de $5 \mathrm{~mm}$ es muy limitada.

\section{¿Existe inflamación de los tejidos blandos periim- plantarios?}

Si la mucosa periimplantaria no muestra signos de inflamación y la sonda no penetra más de $3 \mathrm{~mm}$, el implante suele estar colonizado por bacterias que no son periimplantopatógenas (Cocos Gram +). En el otro extremo, si existen bolsas más profundas de 5 $\mathrm{mm}$, la probabilidad de que se desarrolle un proceso inflamatorio es mayor. La tumefacción y el enrojecimiento pueden estar presentes o no, siendo la presencia de pus un signo claro de infección periimplantaria en actividad.

\section{¿Hay perdida de hueso periimplantario?}

El diagnóstico diferencial de periimplantitis requiere diferenciarla de las inflamaciones reversibles sin pérdida de soporte. De este modo, ante la presencia de bolsas mayores de $3 \mathrm{~mm}$, más allá del hombro del implante, está indicado un examen radiográfico para evaluar la morfología del hueso periimplantario

\section{¿Puede existir otra causa que provoque la apari- ción de pseudobolsas?}

Es posible encontrar situaciones en las que la pérdida de soporte haya ocurrido después de la cirugía de inserción de implantes, por inserción profunda del implante dentro de hueso, y una vez que la anchura biológica se establezca de forma definitiva, quedando entonces la altura del hueso a un nivel más apical. Otras veces la pérdida ósea presente en un implante puede deberse a un fallo parcial en la consecución de la osteointegración, quedando parte de la longitud del implante, la zona más coronal, ausente de recubrimiento óseo.

De esta forma, el diagnóstico de Periimplantitis queda perfectamente descrito en los Proceedings of the 3rd European Workshop on Periodontology (21), como la presencia de una serie de signos clínicos irrefutables:

- Debe existir evidencia radiológica de destrucción vertical de la cresta ósea. Esta pérdida ósea comienza produciéndose en la parte coronal del implante, mientras que la parte más apical del implante sigue estando rodeada de hueso, siendo suficiente para mantener la inmovilidad del mismo. Esta destrucción puede progresar sin signos de movilidad hasta que la destrucción ósea consigue destruir por completo la osteointegración conllevando a la explantación del implante

- Esta destrucción ósea vertical se asocia con la formación de bolsas periimplantarias.

- Hay sangrado después del sondaje suave, pudiendo existir supuración de la bolsa. 
- Los tejidos blandos marginales pueden estar inflamados, tumefactos y enrojecidos, aunque su presencia no es imprescindible para el diagnóstico. La hiperplasia es frecuente en áreas de implantes rodeados de mucosa que no es queratinizada, o en casos en los que la supraestructura protésica es una sobredentadura.

- La presencia de dolor no es un signo frecuente de periimplantitis, cursando gran parte de ellas en ausencia del mismo.

Por otro lado, implantes con periimplantitis pueden permanecer estables durante mucho tiempo, hasta que se pierda por completo la osteointegración, con independencia de la cantidad y severidad de la inflamación, y del sangrado y profundidad del sondaje. De esta forma no debemos considerar que la aparición de periimplantitis sea sinónimo de implante fracasado, aunque si esta situación inflamatoria no se controla podemos llegar a la pérdida total de la osteointegración.

\section{TRATAMIENTO}

Una vez realizado el análisis diagnóstico previamente descrito sobre la repuesta inflamatoria de los tejidos periimplantarios, y los datos más relevantes de las características de superficie y morfología de los implantes que puedan influir sobre la aparición de periimplantitis, así como de la flora periimplantopatógena, estamos en disposición de afrontar la terapéutica de este problema. Evidentemente, el principal objetivo del tratamiento de la periimplantitis es detener la progresión de la pérdida de hueso, controlando la infección bacteriana.

A lo largo de los últimos años se han ensayado y publicado múltiples protocolos de mantenimiento y tratamiento, basados fundamentalmente en estudios experimentales en animales, en la aplicación por extensión de protocolos de tratamiento de la periodontitis, y por supuesto en la propia experiencia clínica de los profesionales. Además, no existe información contrastada sobre distintos protocolos de mantenimiento de implantes en el paciente periodontal, pero como el mantenimiento periodontal está bien protocolizado, es la única referencia disponible en estos casos (23)

Si hay coincidencia en estos protocolos, en la necesidad de realizar un enfoque preventivo y un diagnóstico precoz, al igual que hacemos en la periodontitis, que nos disminuya los efectos negativos y progresivos de estos procesos infecciosos, ya que aunque parece que la prevalencia de la periimplantitis es baja, cuando ocurre la progresión suele ser mucho más rápida que en la periodontitis, llegando a destrucciones masi- vas del soporte óseo periimplantario, a veces con una velocidad de progresión vertiginosa. Como bien sabemos, los dientes infectados periodontalmente pueden contaminar a los implantes insertados en la misma boca. Por ello es necesario controlar la enfermedad periodontal de forma previa a la terapia con implantes, manteniendo unas bolsas menos profundas y en todo momento controladas (24) (Fig. 5) para evitar la contaminación del surco periimplantario (Fig. 6).

El tratamiento de la infección periimplantaria tiene varios aspectos, siendo necesario considerar todos para conseguir la curación. En primer lugar es necesaria la eliminación de la bolsa de las bacterias causante, junto con la descontaminación de la superficie del implante, la reducción o eliminación de los zonas que no pueden ser mantenidas libre de placa por medio de las maniobras de higiene oral, para evitar la recontaminación o la aparición de mucositis periimplantaria, y en último término la regeneración del hueso destruido (22).

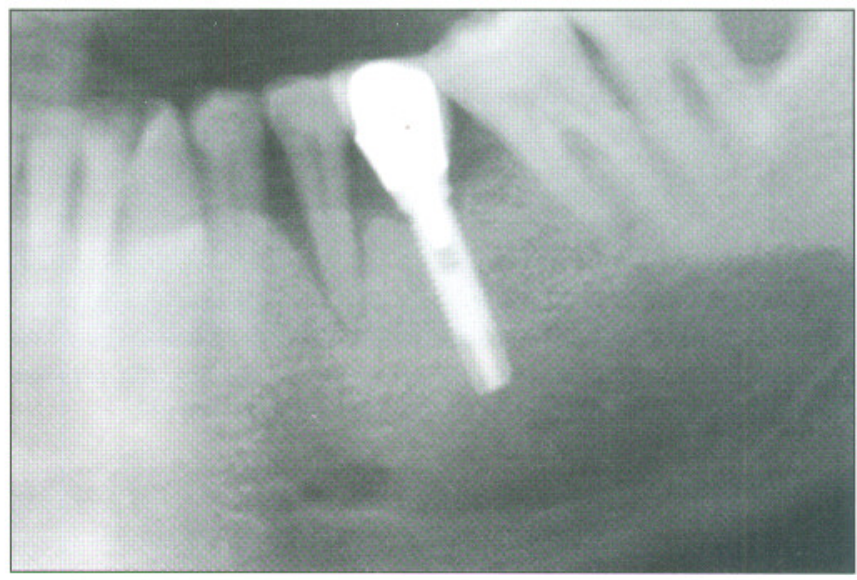

Fig. 5a. Radiografía de implante adyacente a un diente con defecto óseo periodontal sin tratar.

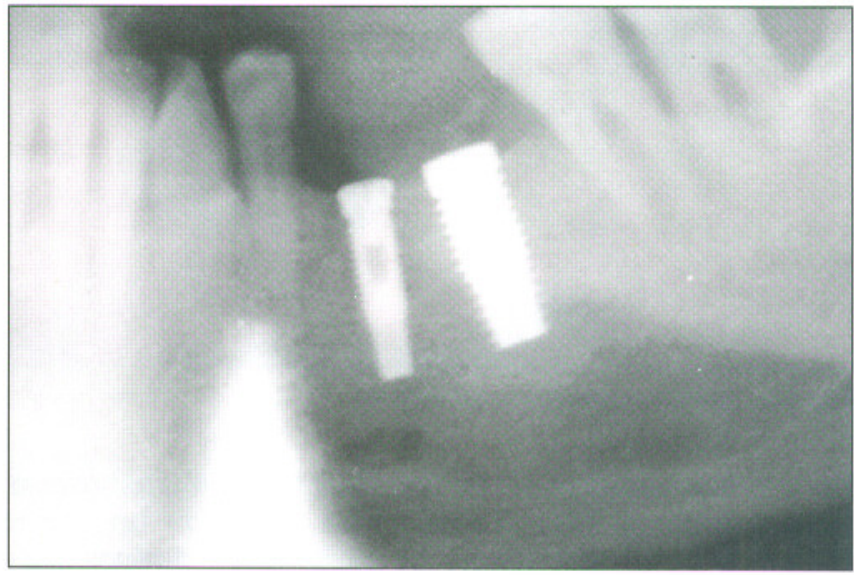

Fig. 5b. Radiografía del caso anterior después de perder el diente con severa afectación periodontal y el implante por periimplantitis. 


\section{AVANCES}

Volumen 16 - No 1 - Abril 2004

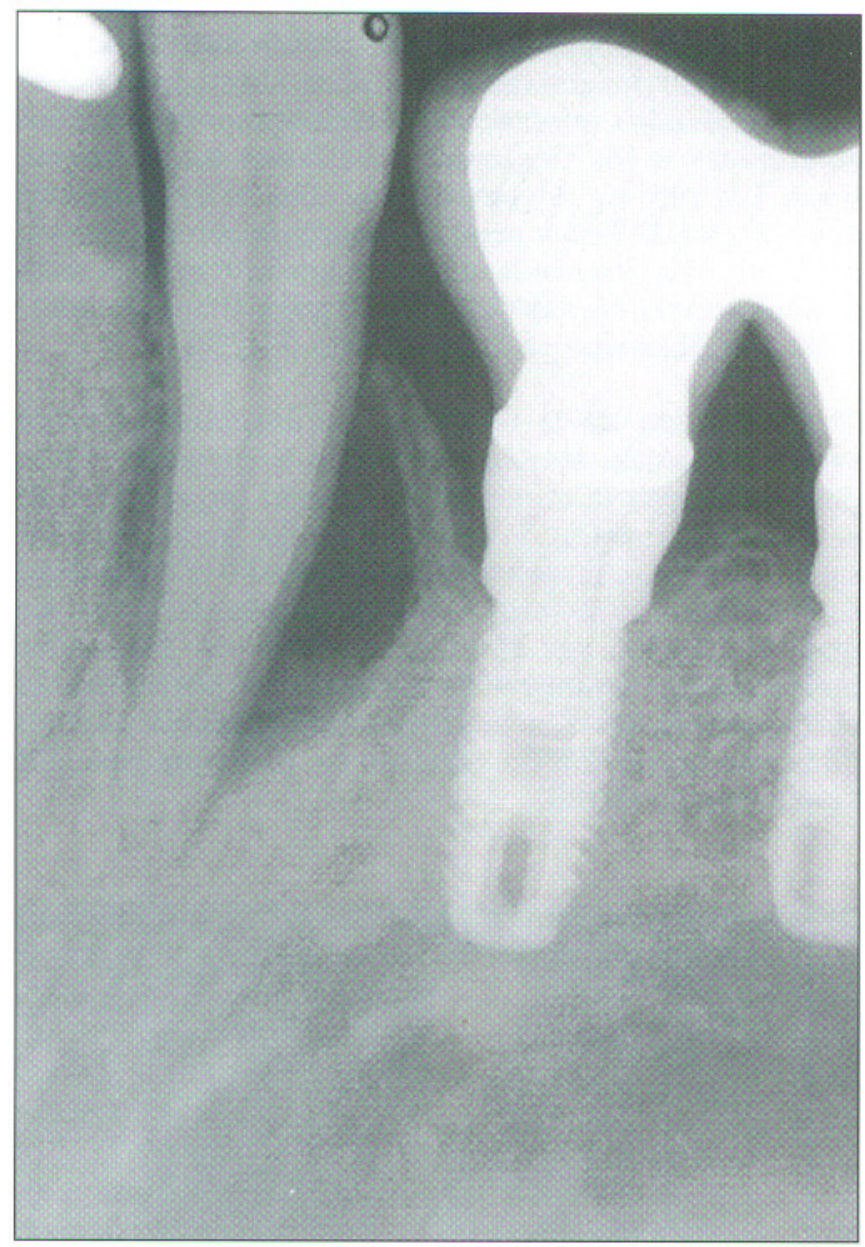

Fig. 6a. Tratamiento de defecto periodontal. Diente con servero defecto periodontal adyacente a implantes sano en función.

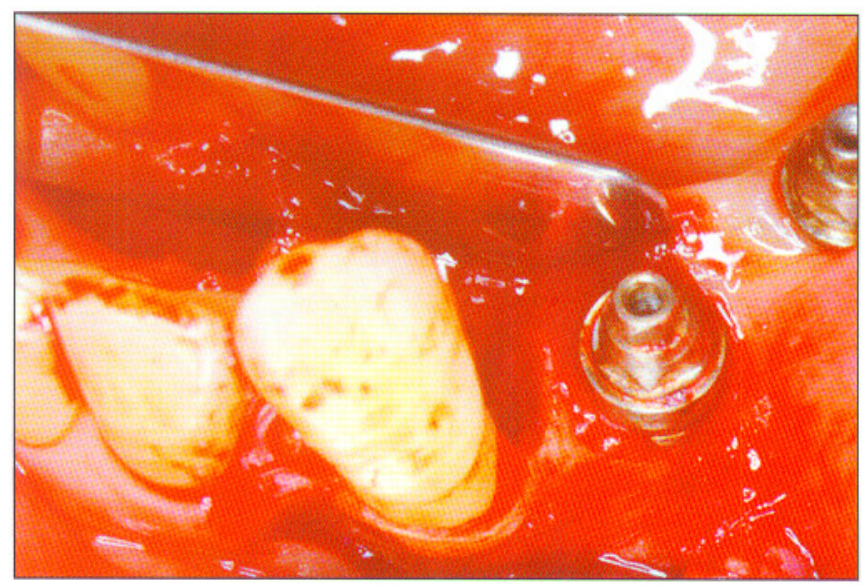

Fig. 6b. Abordaje quirúrgico del defecto.

En los Proceedings of the 3rd European Workshop on Periodontology (21) (Tabla 1) se describe un árbol lógico de actuación dónde los parámetros clínicos usados son la dimensión de la bolsa periimplantaria, la evidencia de pérdida de hueso, la presencia de placa

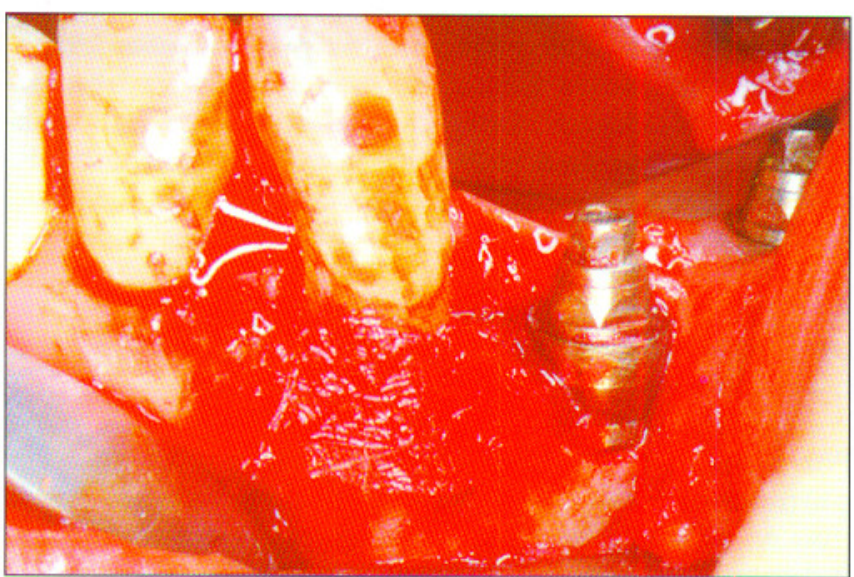

Fig. 6c. Colocación de membrana para regeneración periodontal.

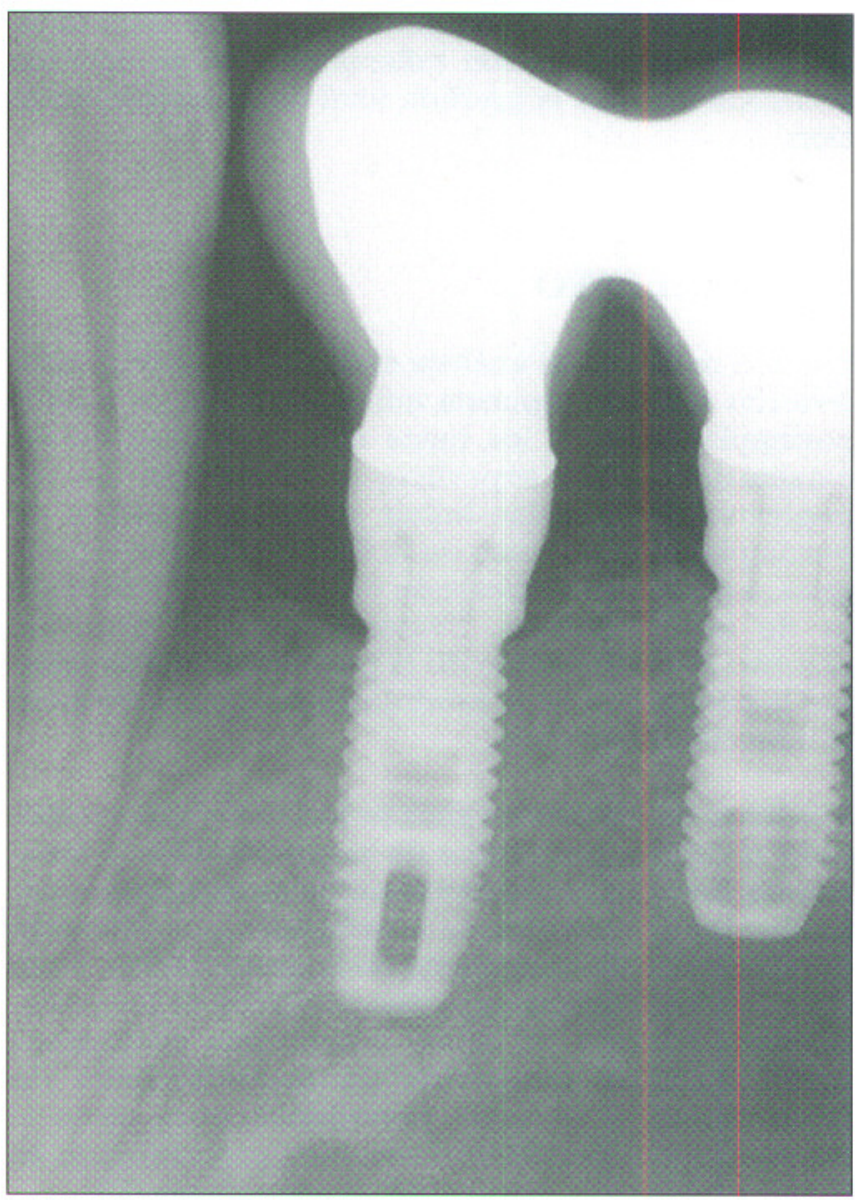

Fig. 6d. Radiografía del defecto regenerado, evitando la progresión hacia el implante.

bacteriana y el sangrado al sondaje, dando diferentes opciones terapéuticas en función de la presencia o ausencia de algunos de estos parámetros clínicos.

Así, ante la presencia de placa bacteriana en bolsas periimplantarias con dimensiones menores de $4 \mathrm{~mm}$ y 


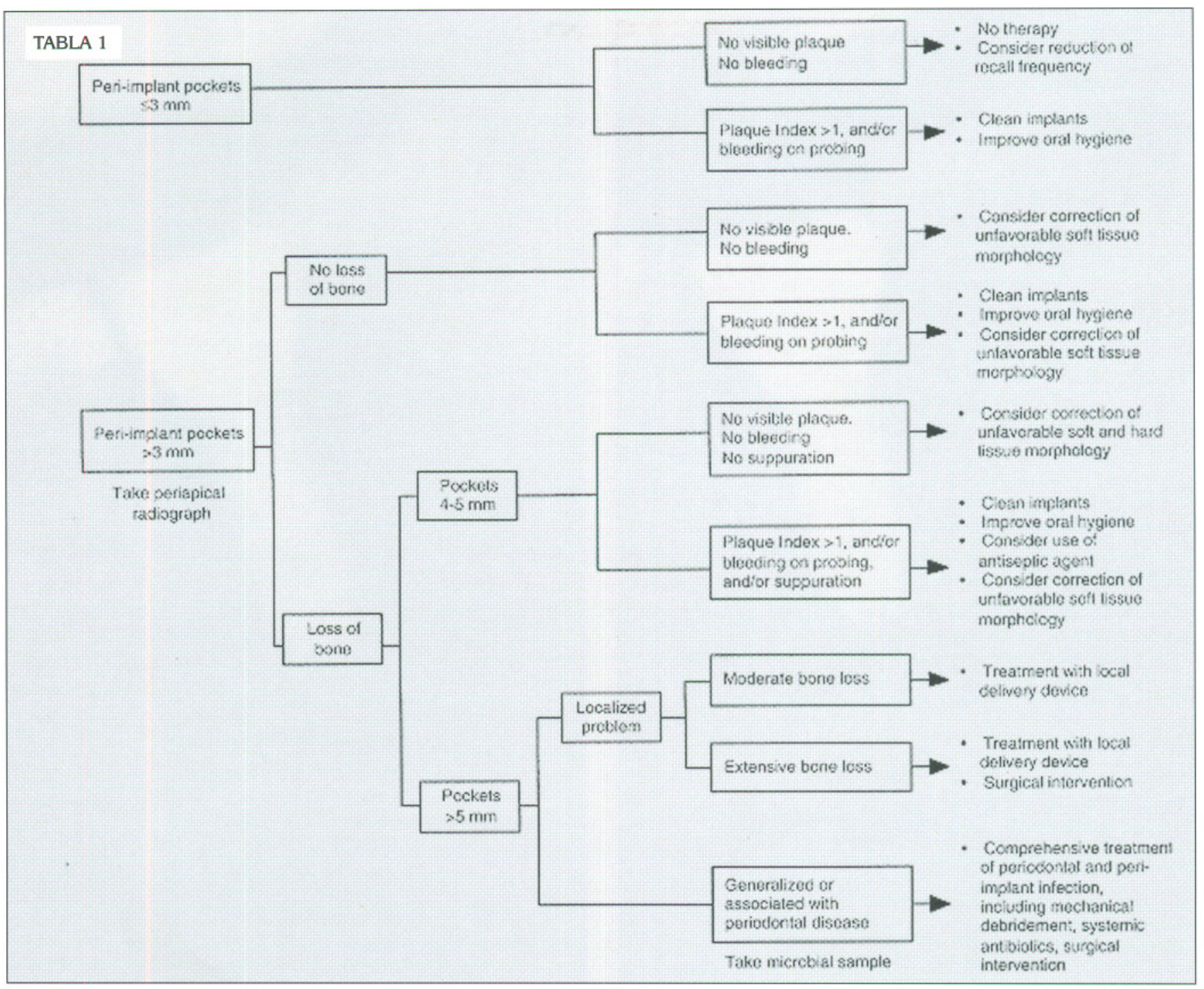

que sangren al sondaje suave, aplicaremos el nivel $\mathrm{A}$ de tratamiento consistente en limpieza mecánica y mejora de la higiene oral del paciente. La remoción de los depósitos duros alrededor de los pilares y de las prótesis se realizará con curetas e instrumentos con punta activa blandas, ya sean de plástico o de metales blandos que no rayen la estructura pulida de los componentes de titanio, para después realizar un pulido exhaustivo con copas de goma y pasta no abrasiva, haciendo mucho hincapié en la enseñanza del paciente en las normas y cuidados de higiene oral domésticos.

En aquellas situaciones en la que nos encontremos ante la presencia de placa y sangrado al sondaje, pero con bolsas periimplantarias de $4-5 \mathrm{~mm}$, será necesaria la realización de un control radiológico de la altura del margen óseo para evaluar de forma comparativa con radiografías anteriores, la presencia o no de pérdida ósea. Si no existiera esta pérdida a las medi- das terapéuticas descritas en el nivel A añadiríamos la utilización de terapia antiséptica, recomendando el uso de enjuagues con digluconato de clorhexixina al $0,1-0,2 \%$, irrigación de la bolsa con soluciones de clorhexidina al 0,2 \% o la aplicación local de geles de clorhexidina (nivel B).

Si la profundidad de sondaje fuera mayor de $5 \mathrm{~mm}$, y hubiera sangrado al sondaje será necesario añadir al nivel $\mathrm{B}$ de tratamiento la administración de terapia antibiótica, habida cuenta de la dificultad de llegar el colutorio al interior de la bolsa, ya sea con procedimientos de inserción en el interior de la bolsa de dispositivos de liberación local de antibióticos, o con antibióticos por vía general, previo estudio microbiológico de detección específica de patógenos y posterior cultivo y antibiograma (nivel C).

Por último ante la presencia de la misma situación clí- 


\section{AVANCES}

Volumen 16 - No 1 - Abril 2004

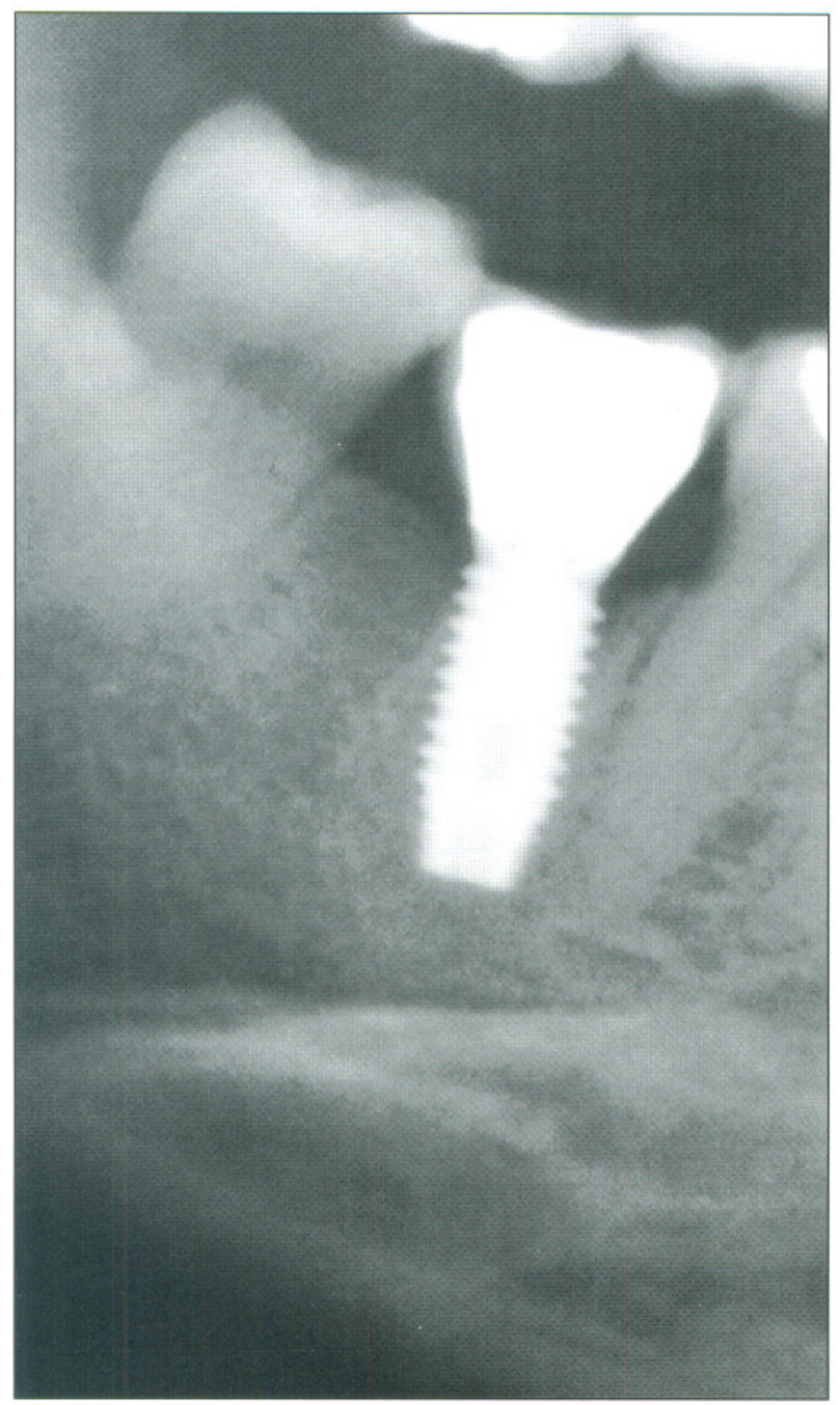

Fig. 7a. Tratamiento de implante afectado de periimplantitis: Radiografía de implante en la inserción de la corona protésica.

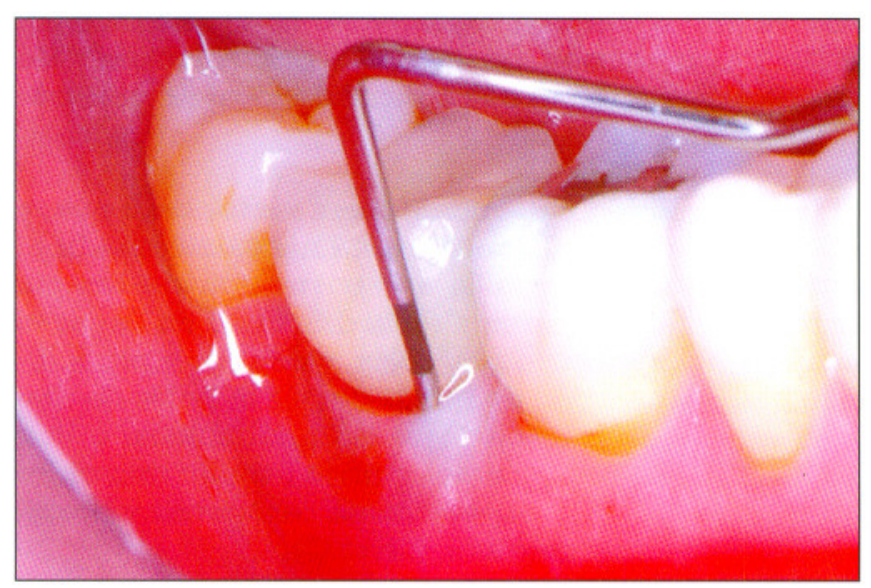

Fig. 7c. Sondaje del defecto periimplantario.

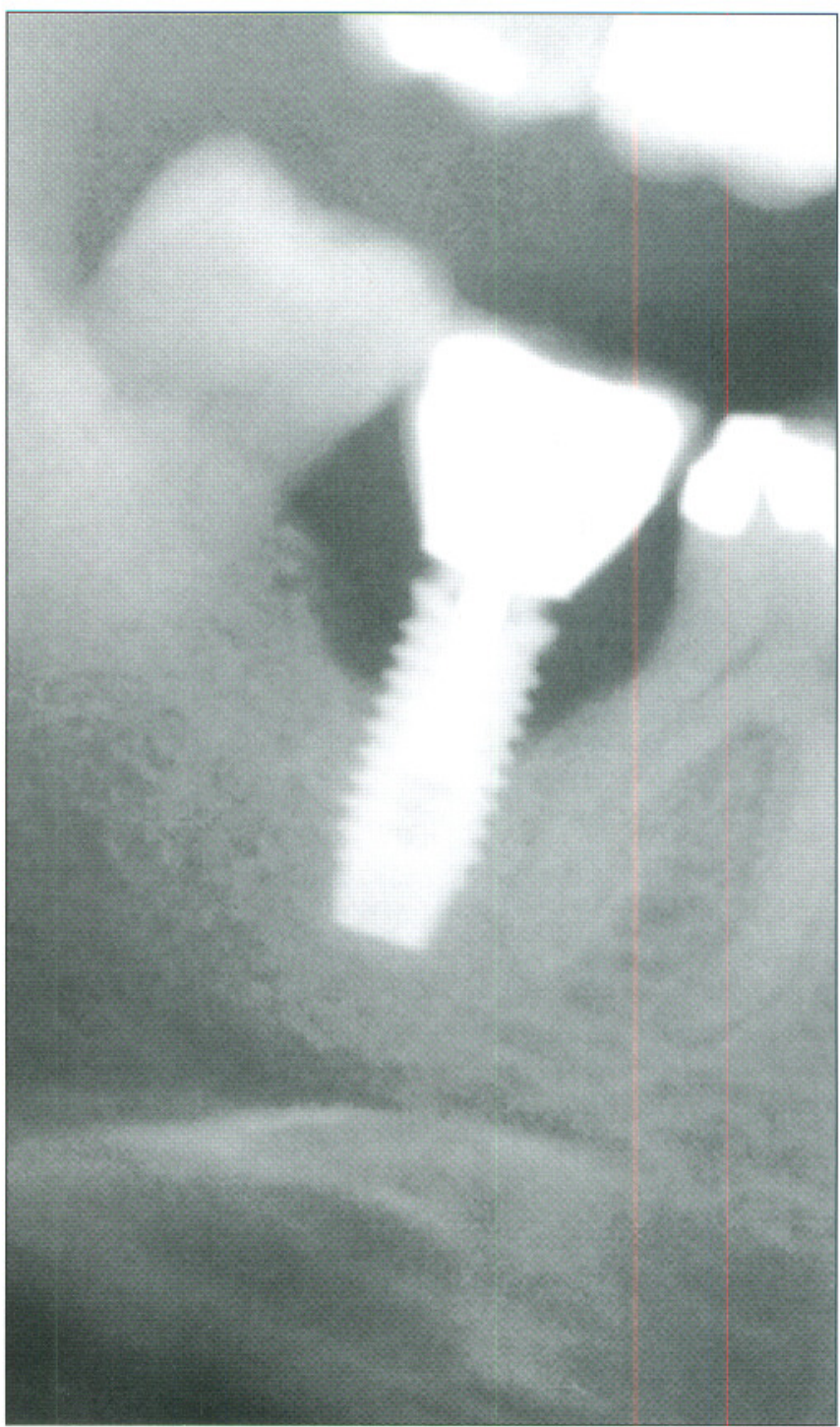

Fig. 7b. Radiografía del implante después de 3 años sin acudir a revisiones.

nica anterior pero con evidencia radiológica de pérdida de hueso estará recomendado en nivel D de tratamiento consistente en ampliar la oferta terapéutica con tratamiento quirúrgico para modificar o cambiar la morfología de los tejidos periimplantarios. La finalidad del tratamiento quirúrgico es modificar la morfología de los tejidos blandos y del defecto óseo provocado por la enfermedad periimplantaria, además de conseguir un área de fácil mantenimiento para el paciente.

En definitiva, será la forma y tamaño del defecto la que determine el tipo de cirugía a realizar, resectiva o regenerativa. La terapia resectiva estará indicada para reducir bolsas, corregir la arquitectura ósea negativa y modificar la rugosidad de la superficie de los implantes afectados, así como para conseguir un 


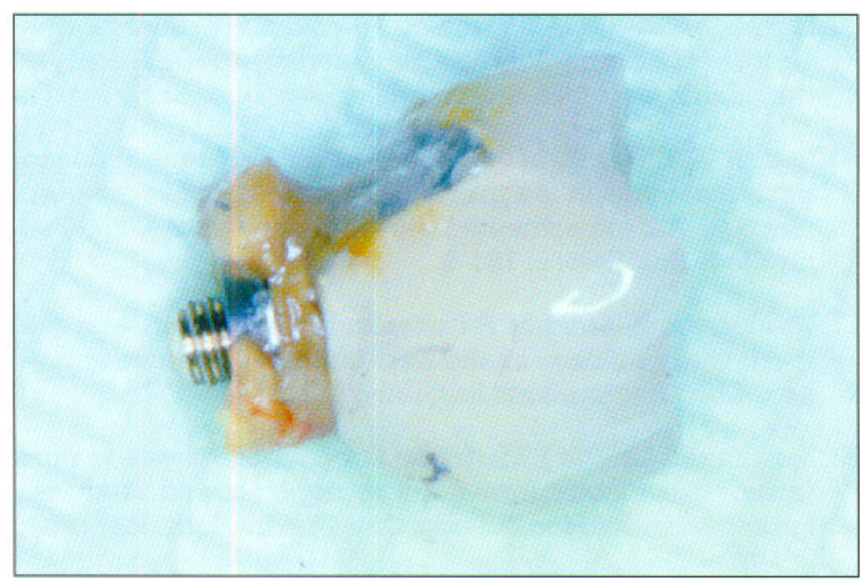

Fig. 7d. Corona protésica desatornillada.

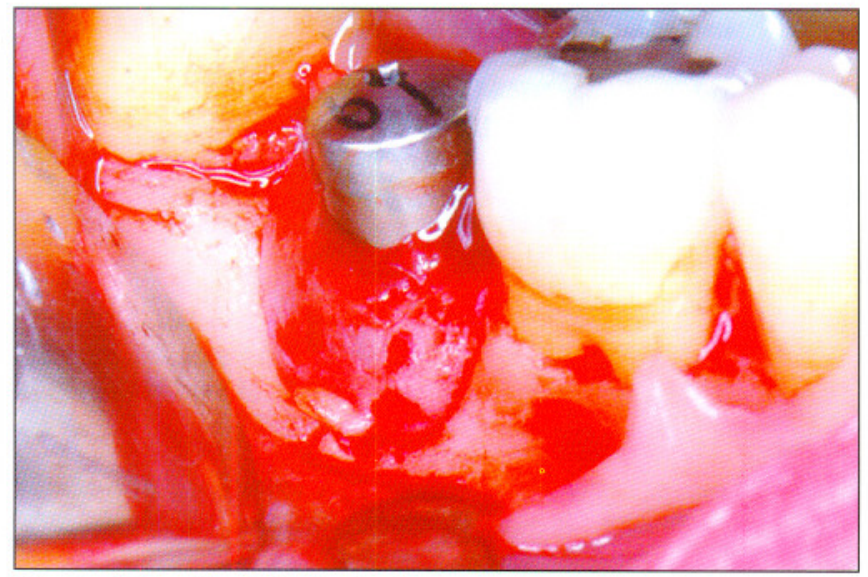

Fig. 7e. Elevación del colgajo de acceso.

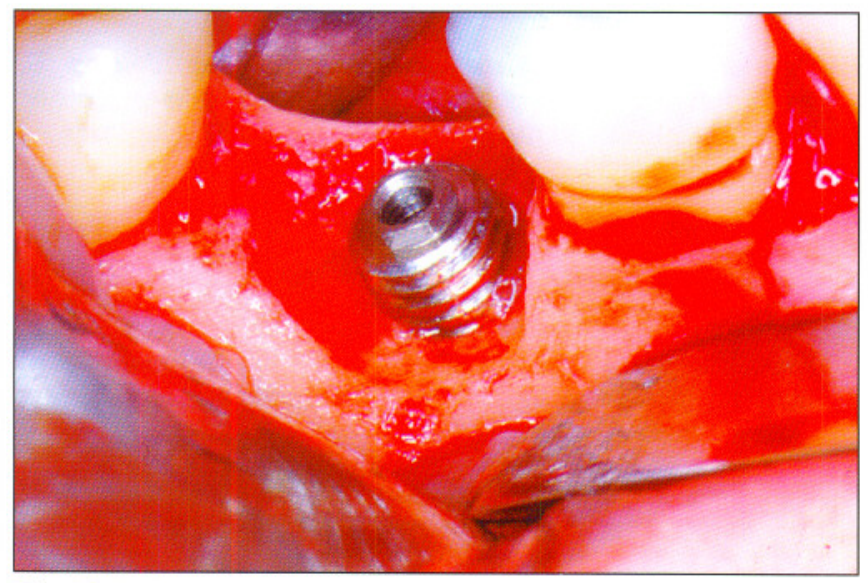

Fig. 7f. Defecto periimplantario.

incremento del área de encía insertada queratinizada, si fuera necesario. La cirugía regenerativa también estará indicada para reducir el tamaño de las bolsas y defectos óseos, pero no con el sentido de eliminar tejido sino con el objetivo de regenerar el hueso perdido (Fig. 7).

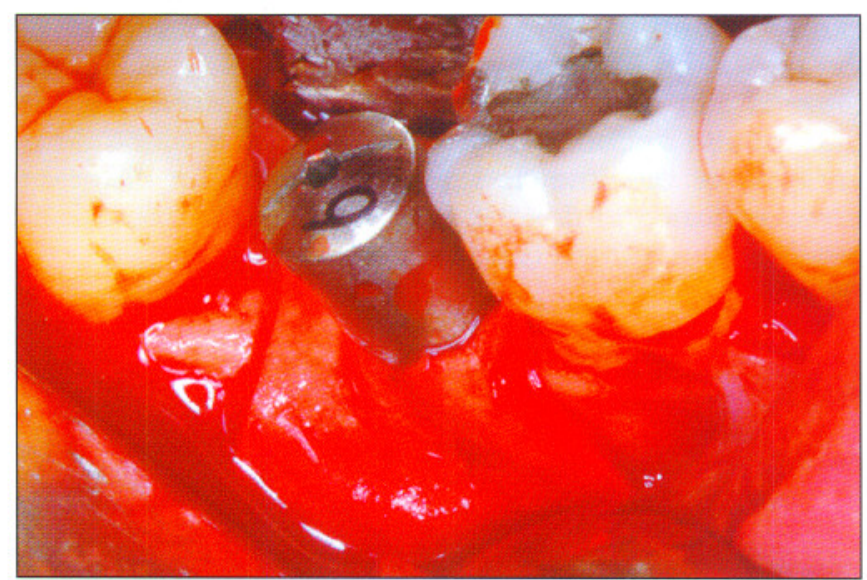

Fig. 7g. Colocación de membrana de regeneración ósea.

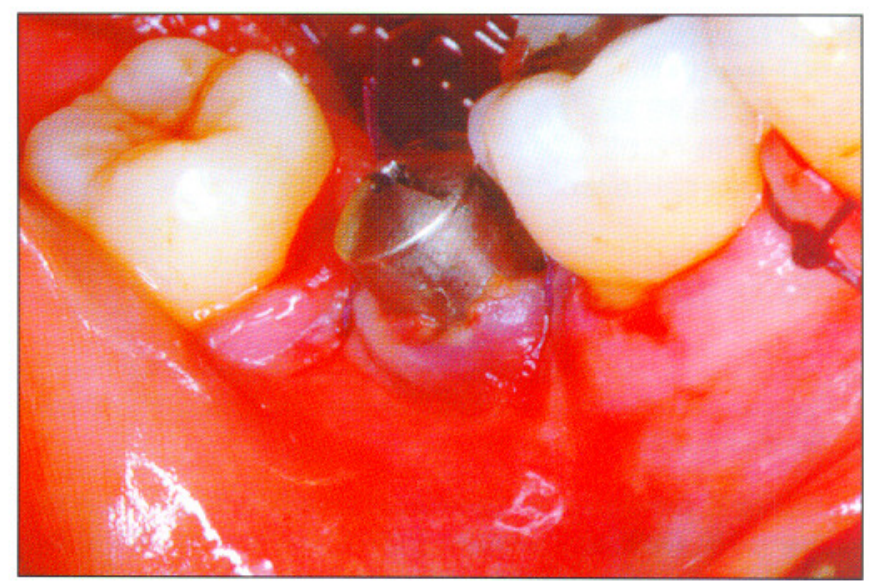

Fig. 7h. Sutura del colgajo.

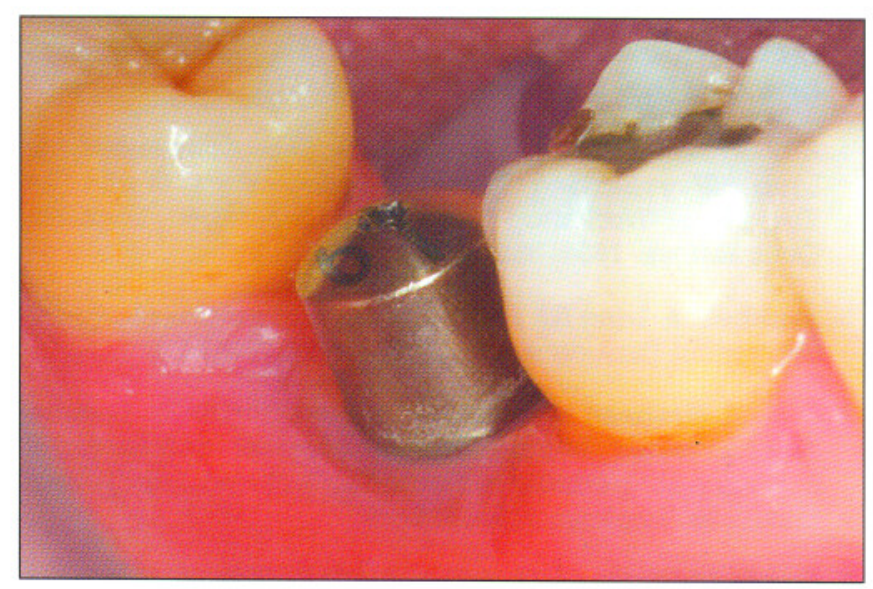

Fig. 7i. Cicatrización de los tejidos periimpalntarios.

\section{ABSTRACT}

In the present work, we describe the most important investigations and findings that have appeared in the recent implantology literature and are more signifi- 
cantly related to clinical diagnosis and applications in the treatment of periimplantitis by dentists. Although there is still no clarity or consensus on protocols for therapeutic action, we have performed a meticulous analysis of the knowledge contributed by different investigators and describe its most reasonable application in the light of the latest research.

\section{KEY WORLDS}

Periimplantitis. Diagnosis. Treatment.

\section{CORRESPONDENCIA}

Manuel García Calderón

Avda. Luis Montoto 117, $1^{\circ}$

41007 Sevilla

Telf: 954581828

Fax: 954580505

e-mail: mgcalderon@teleline.es

\section{BIBLIOGRAFÍA}

1. Klokkevold PR, Newman MG. Current status of Dental Implants: A Periodontal perspective. Int J Oral Maxillofac Implants 2000; 15: 56-65.

2. Nilner K, Lundgren D. Consensus report of Session E. . En: Lang NP, Karring T Lindhe J ed. Proceedings of the 3rd European Workshop on Periodontology. Berlin: Quintessence Verlag, 1999: 457-61.

3. Isidor F. Loss of osseointegration caused by occlusal load of oral implants. A clinical and radiographic study in monkeys. Clin Oral Impl Res 1996; 7: 143-52.

4. Albrektsson T, Isidor F. Consensus report of session IV. En: Lang NP y Karring T (eds.). Proceedings of the lst European Workshop on Periodontology. Londres: Quintessence 1994: 365-9.

5. Mombelli $\AA$, Lang NP. The diagnosis and treatment of periimplantitis. Periodontology 2000, 1998; 17: 63-76.

6. Sanz M, Newman MG y cols. Characterization of the subgingival microbial flora around endosteal saphire dental implants in partially edentulous patients. Int J Oral Maxillofac Implants 1990; 5: 31-8.

7. García-Calderón M, Gutiérrez-Pérez JL, Gómez de la Mata J. Evaluación clínica del paciente susceptible de tratamiento con implantes. Aspectos epidemiológicos. Indicaciones. En: Gutiérrez-Pérez JL y García-Calderón M (eds.). Integración de la Implantología en la Práctica Odontológica. Ediciones Ergón. Madrid, 2002.

8. Berglund T, Lindhe J, Marinello C y cols. Soft tissue reation to de novo plaque formation on implants and teeth. An expeimental study in the dog. Clin Oral Implants Res 1992; 3: $1-8$
9. Lindhe J, Berglundh T Ericsson I y cols. Experimental breakdown of peri-implant and periodontal tissues. A study in the beagle dog. Clin Oral Implants Res 1992; 3: 9-16

10. Warrer K, Buser D, Lang NP y Karring T. Plaque-induced peri-implantitis in the presence or absence of keratinized mucosa. An experimental study in monkeys. Clin Oral Implants Res 1995; 6: 131-8.

11. Wennstrom Jl, Bengazi F, Lekholm U. The influence of the masticatory mucosa on the peri-implant soft tissue condition. Clin Oral Implants Res 1994; 5: 1-8.

12. Berglund T, Lindhe J, Marinello $\mathrm{C}$ y cols. Soft tissue reation to de novo plaque formation on implants and teeth. An expeimental study in the dog. Clin Oral Implants Res 1992; 3: 1-8.

13. Pontoriero R, Tonetti MP, Carnevale G y cols. Experimentally induced peri-implant mucositis. A clinical study in humans. Clin Oral Implants Res 1994; 5: 254-9.

14. Mombelli A, Lang NP. Microbial aspects of implant dentistry. Periodontol 2000 1994; 4: 74-8.

15. Salcetti JM, Moriary JD, Cooper LF y cols. The clinical, microbial, and host response characteristics of the failing implants. Int J Oral Maxillofac Implants 1997; 12: 32-42.

16. Ericsson I, Person LG, Berglund T y cols. The effect of antimicrobial therapy on periimplantitis lesions An experimental study in the dog. Clin Oral Implant Res 1996; 7:3208.

17. Mombelli A, Lang NP. Antimicrobial treatment of periimplant infections. Clin Oral Implant Res 1992; 3: 162-8.

18. Becker W, Becker BE, Newman MG, Nyman S. Clinical and microbiologic findings that may contribute to dental implant failure. Int J Oral Maxillofac Implants 1990; 5: 31-8.

19. Danser MM, van Winkelhoff AJ, van der Velden U. Periodontal bacteria colonizing oral mucosus membranes in edentulous patients wearing dental implants. J Periodontol 1997; 68: 209-16.

20. Mombelli A, Lang NP. The diagnosis and treatment of periimplantitis. Periodontology 2000, 1998; 17: 63-76.

21. Mombelli A. Prevention and therapt of peri-implant infections. En: Lang NP, Karring T Lindhe J (eds). Proceedings of the 3rd European Workshop on Periodontology. Berlin: Quintessence Verlag, 1999: 281-303.

22. Mombelli A. Microbiology and antimicrobial therapy of peri-implantitis. Periodontology 2000 2002; 28: 177-89.

23. Noguerol B, Sicilia A. Los implantes en el tratamiento del paciente periodontal. En: Gutiérrez-Pérez JL y GarcíaCalderón M (eds.). Integración de la Implantología en la Práctica Odontológica. Ediciones Ergón. Madrid, 2002.

24. Salcetti JM, Moriarty JD, Cooper LF y cols. The clinical, microbial, and host response characteristics of the failing implant. Int J Oral Maxillofac Implants 1997; 12: 32-42. 